\title{
Using SNOT - 22 as a decision making tool in performing Nasal Surgery
}

${ }^{1}$ Drahaman A. M. P., ${ }^{2}$ Henney S. E.

${ }^{1}$ International clinical fellow in ENT (SpR), Warwick Hospital

${ }^{2}$ Consultant ENT Surgeon, Warwick Hospital, United Kingdom

\section{Introduction.}

Listing a patient for a nasal surgery, be it a 'Closed' septoplasty or Functional endoscopic sinus surgery (FESS) has always been a clinical decision taken by the attending surgeon. Although in most instances clear indications exist for surgical intervention, there are times when this is unclear. Supportive evidence to help the clinician make the right surgical decision in these circumstances is vital.

We hope to find the magic number (SNOT 22 score) for each surgery which will support the clinical decision taken by the treating physician when listing a patient for surgery.

We also aim to prove that the improvement in SNOT 22 scores following surgery further reinforces that the correct surgical decision has been made with regard to surgery.

\section{Literature review}

SNOT 22 is an ENT UK CAPAG (Clinical Audit and Practice Advisory Group) approved patient reported outcome measure and is routinely used in clinical practice to highlight the impact of nasal disease and to measure the effectiveness of surgical intervention ${ }^{1}$. The questionnaire consists of 22 questions and are grouped as questions pertaining to nasal symptoms, ear symptoms and independent variables respectively. It has also been used to predict postsurgical improvement in patients with chronic sinusitis ${ }^{2}$. Most recently it has been used to evaluate the success of FESS and septoplasty surgery ${ }^{3}$. It has also been used as supportive evidence for treatment of Rhinosinusitis ${ }^{4}$. However its usage as a tool to support a surgical decision/ intervention has rarely been documented.
Indications for individual nasal surgeries are varied from one standard text to another. Below are some of the indications obtained from standard text $t^{5,6}$.

ESS (Endoscopic Sinus Surgery)

1. Chronic rhinosinusitis

2. Acute recurrent rhinosinusitis

3. Nasal polyposis

4. Mucocoeles

5. Allergic fungal sinusitis and mycetoma

6. Repair of cerebrospinal fluid (CSF) leaks

7. Orbital and optic nerve decompression

8. Repair of blow-out fractures

9. Dacrocystorhinostomy (DCR)

10. Choanal atresia

11. Hypophysectomy

12. Septal and turbinate surgery

13. Management of epistaxis

14. Drainage of periorbital abscess

\section{Septoplasty}

1. When septal deformities have to be dealt with as part of a rhinoplasty.

2. When there is a dislocation of the caudal end of the quadrilateral cartilage.

3. When deviation of the cartilaginous part of the nose is external and cosmetically unacceptable;

4. Nasal Obstruction

5. To gain surgical access

1. To pass instruments (FESS)

2. Hypophysectomy 

6. Source of grafting material
7. Anterior Ethmoid syndrome
8. Epistaxis

\section{Objectives}

1. To find out specific SNOT 22 scores for each individual type of Nasal operation that was listed for surgery

2. To evaluate whether the SNOT 22 scores can be used as supportive evidence for listing a patient for Nasal Surgery

3. To evaluate success of the listed Nasal Surgeries (By analysing post-operative SNOT 22 scores)

\section{Material and Methods}

A prospective observational study was planned on randomly selected patients undergoing nasal surgery at Warwick hospital from the $1^{\text {st }}$ of June to the $31^{\text {st }}$ of August 2015. Ethical approval was obtained from the ethics committee of Warwick hospital and a research number was obtained.

The selected patients were registered into the study in accordance with the inclusion and exclusion criteria listed below.

- Inclusion Criteria

1. Patients undergoing Septoplasty

2. Patients undergoing Balloon Sinuplasty

3. Patients undergoing Turbinate surgery

4. Patients undergoing FESS (Functional Endoscopic Sinus Surgery)

5. Patients undergoing Nasal Polypectomy

6. Patients undergoing any combination of the above

\section{- Exclusion Criteria}

1. Patients listed as emergency

2. Patients having significant co morbid factors

Data collection was done by administering the structured questionnaire (SNOT 22) preoperatively as well as post operatively within a three month period. The annexed data was then tabulated under Microsoft Excel 2015 and analysed.

\section{Results}

A total number of 111 patients were analysed preoperatively of which 62 were able to contribute post-operative data. (Refer Chart 1) When listing patients for combined FESS surgery a mean score of $47.97+/-18.92$ (SD) was obtained. If only FESS was listed then the score dropped to $45.48+/-18.39$ (SD) the highest listing score was obtained by patients listed for FESS and balloon Sinuplasty which was $54+/-22.67$ (SD). Overall patients requiring some sort of surgical intervention for their nasal symptoms scored $43.56+/-$ 19.88. (Refer Table 1)

When these results were analysed alongside post-operative values, patients undergoing FESS combined surgery showed a mean improvement in scores of $26.34(\mathrm{P}<0.04)$. This was in contrast to patients undergoing septoplasty and septoplasty combined procedures which only showed improvement in scores of 7.5 and 1.6 respectively. The latter had $\mathrm{P}$ values of more than 0.04 making the improvement observed statistically insignificant. (Refer Table 2)

\section{Discussion}

When listing a patient for interventional nasal surgery in addition to his Sino nasal symptoms is important to consider imaging results as well. This may be in the form of a CT nose and paranasal sinus or an MRI of the sinuses. There are various scoring systems with regard to these im- 
aging systems ${ }^{7}$. They can be utilized when making a clinical decision with regard to interventional surgery. However on certain occasions a CT scan alone may not be conclusive enough to warrant intervention. It is on this occasion that the clinician is faced with a dilemma of whether to proceed with the surgery or not.

It is quite clear from the data presented that a number/score can be obtained preoperatively by simply administering a SNOT 22 questionnaire and this can be used to support clinical decision-making when considering treatment options. With reference to Table 1 and taking into consideration the standard deviation we believe that a patient scoring above these numbers would benefit from the below mentioned interventional surgery. Although this would be true for FESS and FESS combined surgery we don't believe application of the scores would be feasible for septoplasty and septoplasty combined surgeries given the relatively high $\mathrm{P}$ values. It is interesting to note that patients listed for septoplasty and septoplasty combined procedures scored significantly less when compared to other surgical procedures. Admittedly the patient numbers undergoing these procedures were relatively low when compared with the other procedures listed as well.

We would like to reiterate that the scoring system is not an alternative to performing a thorough clinical evaluation of the patient but merely an adjunct to support one's clinical decision. Diagnosis of sinusitis is still based on satisfying the EPOS 2012 criteria $^{8}$ and proceeding accordingly.

\section{Key Messages}

Preoperative administration of a SNOT 22 questionnaire can help with making a decision when considering surgical intervention in a patient with persistent nasal symptoms. This can mainly be applied to FESS and FESS combined procedures. If a patient scores more than 43 on his preoperative assessment he may require some sort of surgical intervention in the event medical management has not been successful.

Preoperative SNOT 22 scores should not be used as supportive tool when listing patients for septoplasty and septoplasty combined surgeries.

\section{Chart 1}

Table 1

\begin{tabular}{|l|r|c|c|}
\hline & $\begin{array}{c}\text { Mean } \\
\text { SNOT 22 } \\
\text { SCORE }\end{array}$ & $\begin{array}{c}\text { Stan- } \\
\text { dard } \\
\text { Devia- } \\
\text { tion } \\
\text { (SD) }\end{array}$ & $\begin{array}{c}\text { Num- } \\
\text { ber of } \\
\text { tients }\end{array}$ \\
\hline FESS Combined & 47.97 & 18.92 & 73 \\
\hline FESS only & 45.48 & 18.39 & 30 \\
\hline FESS \& Poly & 51.13 & 18.13 & 18 \\
\hline $\begin{array}{l}\text { FESS Poly \& } \\
\text { Septoplasty }\end{array}$ & 46.67 & 19.76 & 15 \\
\hline $\begin{array}{l}\text { FESS \& Balloon } \\
\text { Sinuplasty }\end{array}$ & 54.00 & 22.67 & 10 \\
\hline Turbinate Sur- & 39.50 & 24.93 & 4 \\
\hline gery & 30.23 & 18.53 & 13 \\
\hline Septoplasty & 29.90 & 16.41 & 21 \\
\hline $\begin{array}{l}\text { Septoplasty \& } \\
\text { Turbinate Sx }\end{array}$ & 43.56 & 19.88 & 111 \\
\hline $\begin{array}{l}\text { Prep scores for } \\
\text { surgical interven- } \\
\text { tion }\end{array}$ & & 111 \\
\hline Totals & & & \\
\hline
\end{tabular}


Table 2

\begin{tabular}{|c|c|c|c|}
\hline & \multicolumn{3}{|c|}{ Post-operative evaluation } \\
\hline & $\begin{array}{c}\text { Mean } \\
\text { im- } \\
\text { prove- } \\
\text { ment of } \\
\text { SNOT } \\
22 \text { score }\end{array}$ & P Value & $\begin{array}{l}\text { Num- } \\
\text { ber of } \\
\text { patients }\end{array}$ \\
\hline FESS Combined & 26.34 & $<0.04$ & 50 \\
\hline FESS only & 24.69 & $<0.04$ & 19 \\
\hline FESS \& Poly & 31.33 & $<0.04$ & 13 \\
\hline $\begin{array}{l}\text { FESS Poly \& } \\
\text { Septoplasty }\end{array}$ & 32.00 & $<0.04$ & 9 \\
\hline $\begin{array}{l}\text { FESS \& Balloon } \\
\text { Sinuplasty }\end{array}$ & 31.11 & $<0.04$ & 9 \\
\hline Septoplasty & 7.50 & 0.1758087 & 7 \\
\hline $\begin{array}{l}\text { Septoplasty \& } \\
\text { Turbinate Sx }\end{array}$ & 1.60 & 0.4160895 & 5 \\
\hline Totals & & & 62 \\
\hline
\end{tabular}

\section{References.}

1. Clin Otolaryngol. 2012 Aug;37(4):276-82. Abdalla S1, Alreefy $H$, Hopkins $C$.

2. Ann Allergy Asthma Immunol. 2013 Oct;111(4):246-251. Kennedy JL1, Hubbard MA, Huyett P, Patrie JT, Borish L, Payne SC.

3. IOSR Journal of Dental and Medical Sciences (IOSR-JDMS) - Volume 6, Issue 5 (May.-Jun. 2013), PP 34-38

4. Journal of Rhinolaryngo-Otologies, 2013, 1, 6-10

5. Scott Brown 7E, Vol 2, Page 1481

6. Scott Brown 7E, Vol 2, Page 1577

7. Lund VJ, Kennedy DW. Staging for rhinosinusitis. Otolaryngol Head Neck Surg 1997; 117: S35-S40

8. Rhinology. 2012 Mar;50(1):1-12. doi: 10.4193/Rhino50E2.

Dr A.M. P. Drahaman

Senior Registar

The National Hospital of Sri Lanka.

E-mail : akramd@gmail.com 